\title{
IgA-Antigliadin antibodies in IgA mesangial nephropathy (Berger's disease)
}

\author{
A FORNASIERI, R A SINICO, P MALDIFASSI, P BERNASCONI, M VEGNI, G D'AMICO
}

\begin{abstract}
Circulating IgA-antigliadin antibodies were detected with enzyme linked immunosorbent assay (ELISA) in four of 121 patients (3\%) who had IgA mesangial nephropathy and 14 of 17 children $(82 \%)$ who had untreated coeliac disease. No positive cases were present in the 54 healthy subjects of the control group. Three patients who had IgA nephropathy and IgA-antigliadin antibodies underwent jejunal biopsy, and two showed mucosal atrophy. In these two patients urinary abnormalities, together with the IgA-antigliadin antibodies, disappeared completely after three months and five months, respectively, of following a gluten free diet. Circulating IgA immune complexes were found in most patients who had coeliac disease and Berger's disease associated with IgA-antigliadin antibodies, suggesting overactivity of the B cells producing IgA in both conditions. By contrast, a circulating IgA rheumatoid factor was detectable in three of the four patients who had IgA nephropathy and asymptomatic coeliac disease but was always absent in children who had coeliac disease but did not show signs of renal disease.
\end{abstract}

These results suggest that a more complex abnormality in the IgA immune response is necessary for renal disease to become manifest in patients who have gluten enteropathy.

\section{Introduction}

There is accumulating evidence that IgA immune complexes (IC) play a part in the development of idiopathic IgA mesangial nephropathy (Berger's disease). ${ }^{1-3}$ Berger's disease is the most common type of chronic glomerulonephritis in many countries throughout the world and is characterised by deposits of material containing IgA in the mesangial region of all glomeruli. ${ }^{4}$

Despite the fact that some episodes of macroscopic haematuria occur immediately after acute mucosal respiratory or gastrointestinal infections a specific exogenous antigen has never been identified. The occurrence of an abnormally increased specific IgA immune response, including the production of $\operatorname{IgA}$ rheumatoid factor, in most patients who have Berger's disease ${ }^{5-7}$ suggests that in predisposed patients even ubiquitous antigens such as dietary antigens could induce a discrete but continuous formation of IgA IC, which become trapped in the renal mesangium and cause glomerular damage. This hypothesis is further supported by evidence of accumulated mesangial deposits of IgA in genetically predisposed strains of mice after alimentary antigen challenge with various proteins. ${ }^{8}$ Dietary antigens that may induce this effect include those related to gluten ingestion, as sporadic cases of IgA

San Carlo Hospital, Milan, Italy

A FORNASIERI, MD, assistant, department of nephrology

R A SINICO, $M D$, assistant, department of nephrology

P MALDIFASSI, MD, research fellow, department of nephrology

P BERNASCONI, PHD, assistant, immunohaematology service

$M$ VEGNI, MD, vice head of department of paediatrics

G D'AMICO, MD, professor, head of department of nephrology

Correspondence to: Dr A Fornasieri, Divisione di Nefrologia, Ospedale San Carlo Borromeo, 20100 Milan, Italy.

Request for reprints to: Professor G D’Amico, Divisione di Nefrologia, Ospedale San Carlo Borromeo, Milan, Italy. mesangial nephropathy have been described in patients who had coeliac disease or dermatitis herpetiformis..$^{910}$

We report here the presence of circulating IgA-antigliadin antibodies in 121 consecutive patients who had idiopathic $\operatorname{IgA}$ mesangial nephropathy.

\section{Patients and methods}

We studied 121 patients ( 88 men, 33 women; mean (SD) age 35 (16), range 11-76) who had IgA glomerulonephritis as shown by biopsy but no signs of hepatic or intestinal disease. The diagnosis was based on the presence of large mesangial deposits of IgA as determined by immunofluorescence microscopy. ${ }^{5}$ Serum samples from 17 untreated children who had coeliac disease were also studied. The diagnosis was based on the presence of characteristic jejunal lesions and on the subsequent favourable clinical and histological responses to withdrawal of dietary gluten. The control group comprised 54 normal subjects (blood donors and laboratory staff) comparable to the patients who had IgA glomerulonephritis in age and sex distribution.

The titres of IgA-antigliadin antibodies were measured with a microenzyme linked immunosorbent assay (ELISA) method with $\alpha$ gliadin prepared according to the method of Kendall et al. ${ }^{11}$ Microplate wells were coated overnight at $4^{\circ} \mathrm{C}$ with $5 \mu \mathrm{g}$ gliadin $/ \mathrm{ml}$ in phosphate buffered saline.

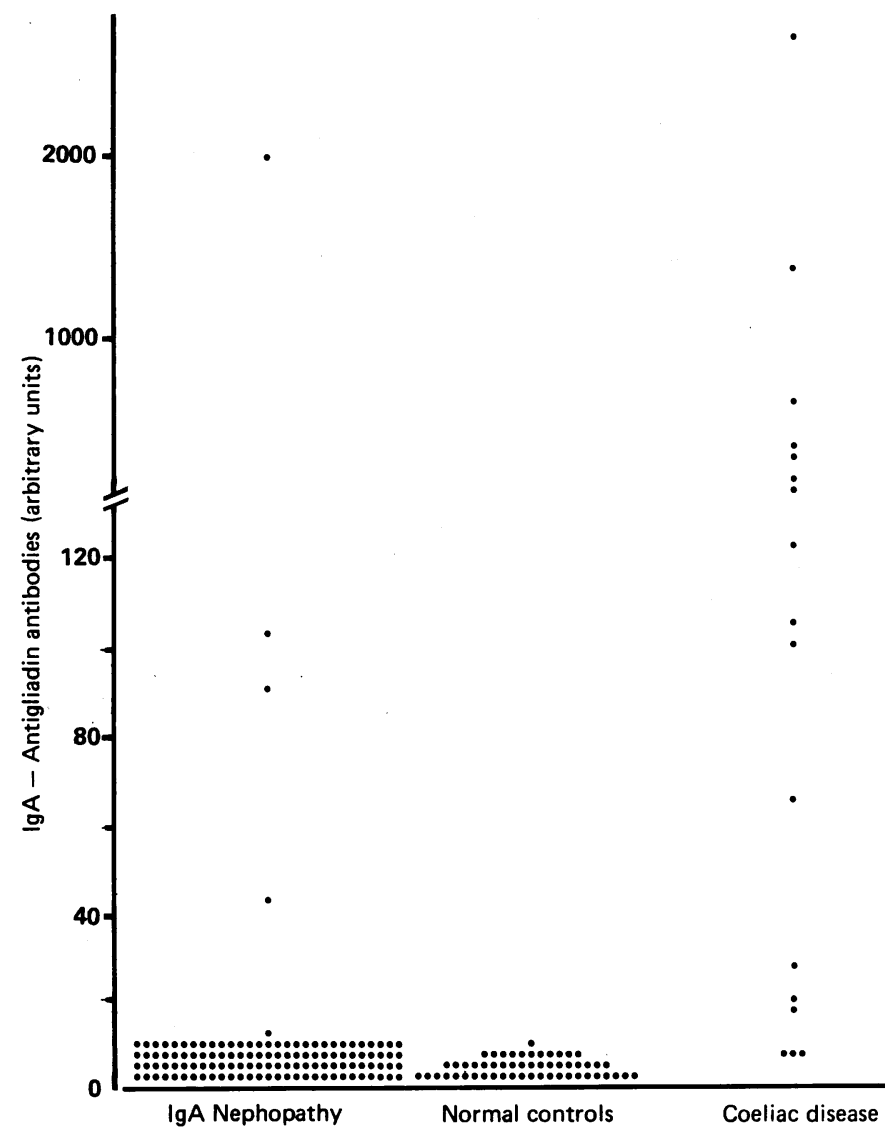

IgA-antigliadin antibodies measured in serum from patients who had IgA nephropathy, from normal controls, and from patients who had coeliac disease. Normal value $<12$ arbitrary units. 
After three washes with phosphate buffered saline containing $0.05 \%$ Tween 20 the plates were blocked by incubating them in phosphate bufferd saline supplemented with $10 \mathrm{mg}$ human serum albumin/ml for two hours at room temperature. After three more washes the plates, were then incubated with serum diluted in phosphate buffered saline-Tween for three hours at room temperature. After washing again $50 \mu \mathrm{l}$ goat antihuman $\alpha$ chain antiserum conjugated with horseradish peroxidase (Cappel) diluted $1 / 1000$ in phosphate buffered saline-Tween was added. After the plates had been incubated for one hour at $37^{\circ} \mathrm{C}$ and washed $50 \mu \mathrm{l}$ substrate was added. The absorbance was read at $405 \mathrm{~nm}$ with a Titertek Multiskan.

The titre of circulating IgA IC was determined with an ELISA modification of the anti-C3 solid phase assay. ${ }^{12}$ IgA rheumatoid factor was measured by ELISA as described, ${ }^{6}$ with plates coated with human IgG and goat $F(a b) 2$ antihuman IgA conjugated with peroxidase.

The results were expressed in arbitrary units for IgA-antigliadin antibody
IgA-antigliadin antibodies and IgA nephropathy (table). These immunological abnormalities disappeared in the two patients who followed a gluten free diet.

\section{Discussion}

Patients who have primary IgA mesangial nephropathy and who never experience recurrent bouts of macroscopic haematuria after upper respiratory tract infections (nearly half of the total population with Berger's disease) progress to renal failure more often and more rapidly. ${ }^{45}$ This observation has prompted the suggestion that in this subgroup a continuous injurious effect, clinically less manifest,

Clinical and immunological data from patients who had IgA nephropathy and high titres of IgA-antigliadin antibodies and from children who had coeliac disease

\begin{tabular}{|c|c|c|c|c|c|c|}
\hline Case No & Sex/age & $\begin{array}{l}\text { Clinical symptoms } \\
\text { of coeliac disease }\end{array}$ & Renal signs & $\begin{array}{l}\text { IgA-antigliadin } \\
\text { antibodies }(\text { arbitrary } \\
\text { units })(\text { normal }<12)\end{array}$ & $\begin{array}{c}\text { IgA } \\
\text { immunocomplexes } \\
\begin{array}{c}\text { (arbitrary units) } \\
(\text { normal }<28)\end{array}\end{array}$ & $\begin{array}{l}\text { IgA rheumatoid } \\
\text { factor }(\mu \mathrm{g} / \mathrm{ml}) \\
(\text { normal }<12)\end{array}$ \\
\hline $\begin{array}{l}1^{\star} \\
2^{\star} \\
3 \\
4^{\star}\end{array}$ & $\begin{array}{l}F / 10 \\
M / 14 \\
M / 8 \\
F / 37\end{array}$ & $\begin{array}{l}\text { No } \\
\text { No } \\
\text { No } \\
\text { No }\end{array}$ & $\begin{array}{l}\text { IgA nephropathy } \\
\text { Recurrent macroscopic haematuria } \\
\text { Recurrent macroscopic haematuria } \\
\text { Recurrent macroscopic haematuria } \\
\text { Recurrent macroscopic haematuria }\end{array}$ & $\begin{array}{r}2000 \\
88 \\
42 \\
102\end{array}$ & $\begin{array}{r}400 \\
<28 \\
31 \\
65\end{array}$ & $\begin{array}{r}115 \\
<8 \\
35 \\
60\end{array}$ \\
\hline $\begin{array}{r}1 \\
2 \\
3 \\
4 \\
5 \\
6 \\
7 \\
8 \\
9 \\
10 \\
11 \\
12 \\
13 \\
14 \\
15 \\
16 \\
17\end{array}$ & $\begin{array}{c}\mathbf{M} / 3 \\
\mathbf{F} / 1 \\
\mathbf{F} / 7 \\
\mathbf{F} / 3 \\
\mathbf{F} / 2 \\
\mathbf{F} / 1 \\
\mathbf{F} / 1 \\
\mathbf{F} / 1 \\
\mathbf{F} / 2 \\
\mathbf{F} / 3 \\
\mathbf{F} / 9 \\
\mathbf{F} / 3 \\
\mathbf{M} / 11 \\
\mathbf{F} / 11 \\
\mathbf{M} / 2 \\
\mathbf{F} / 3 \\
\mathbf{M} / 2\end{array}$ & $\begin{array}{l}\text { Yes } \\
\text { Yes } \\
\text { Yes } \\
\text { Yes } \\
\text { Yes } \\
\text { Yes } \\
\text { Yes } \\
\text { Yes } \\
\text { Yes } \\
\text { No } \\
\text { No } \\
\text { Yes } \\
\text { Yes } \\
\text { Yes } \\
\text { No } \\
\text { No } \\
\text { No }\end{array}$ & $\begin{array}{l}\text { Coeliac disease } \\
\text { None } \\
\text { None } \\
\text { None } \\
\text { None } \\
\text { None } \\
\text { None } \\
\text { None } \\
\text { None } \\
\text { None } \\
\text { None } \\
\text { None } \\
\text { None } \\
\text { None } \\
\text { None } \\
\text { None } \\
\text { None } \\
\text { None }\end{array}$ & $\begin{array}{r}315 \\
418 \\
65 \\
8 \\
30 \\
8 \\
570 \\
110 \\
8 \\
19 \\
2195 \\
170 \\
140 \\
114 \\
1320 \\
17 \\
133\end{array}$ & $\begin{array}{r}400 \\
72 \\
136 \\
<28 \\
37 \\
400 \\
400 \\
400 \\
<28 \\
<28 \\
<28 \\
400 \\
147 \\
44 \\
400 \\
<28 \\
241\end{array}$ & $\begin{array}{l}<8 \\
<8 \\
<8 \\
<8 \\
<8 \\
<8 \\
<8 \\
<8 \\
<8 \\
<8 \\
<8 \\
<8 \\
<8 \\
<8 \\
<8 \\
<8 \\
<8 \\
<8\end{array}$ \\
\hline
\end{tabular}

^Patients who underwent jejunal biopsy; those in cases 1 and 4 had mucosal atrophy.

and IgA IC antibody titres, with strongly positive serum samples as standards, and in $\mu \mathrm{g} / \mathrm{ml}$ for IgA rheumatoid factor. Normal ranges were considered to be those within two SD from the mean values obtained in the control group.

\section{Resuits}

Four (3\%) of the 121 patients who had IgA nephropathy and $14(82 \%)$ of the 17 children who had coeliac disease had high titres of IgA-antigliadin antibodies in their serum (figure). By contrast, no positivity was seen in the healthy control group. Three patients who had antigliadin antibodies (and no symptoms, suggesting gluten enteropathy) underwent jejunal biopsy; two had mucosal atrophy. These two patients, who had had microscopic haematuria for 29 and 36 months, respectively, were prescribed a gluten free diet, with the resulting disappearance of urinary abnormalities (from 5000000 to $26000 \mathrm{red}$ blood cells $/ \mathrm{h}$, and from 2000000 to $15000 \mathrm{red}$ blood cells/h, respectively; normal value 85000 red blood cells/h) and IgAantigliadin antibodies after three and five months, respectively. Moreover, one of these two patients underwent a repeat renal biopsy after 14 months of following a gluten free diet; the biopsy sample showed mild glomerular sclerotic changes under light microscopy and a considerable reduction (only trace amounts) in mesangial deposits of IgA and the disappearance of $\mathrm{C} 3$ under immunofluorescence microscopy.

To characterise further the serological features of the IgA immune response in the patients who had IgA glomerulonephritis and antigliadin antibodies we looked for the presence of IgA IC and IgA rheumatoid factor. We found IgA IC in 12 of the 17 coeliac patients (70\%) and in three of the four patients (75\%) who had IgA nephropathy and IgA-antigliadin antibodies. By contrast, IgA rheumatoid factor was never detected in the 17 coeliac patients whereas it was present in three of the four patients who had could be due to an increased abnormal immune response to constantly available antigens such as autoantigens, food antigens, or exogenous microbial and viral antigens. The defective exclusion of antigens by the gastrointestinal mucosa is possible but improbable in view of the rare association of overt gastrointestinal diseases with primary IgA mesangial nephropathy.

Our results show that IgA-antigliadin antibodies do not play a large part in the development of Berger's disease. Our study also shows, however, that a small population of patients, assumed to have a primary IgA mesangial nephropathy, are in fact affected by gluten enteropathy despite a complete absence of clinical symptoms of coeliac disease. Such a finding has important therapeutical implications, as in the two patients who had circulating IgAantigliadin antibodies and mucosal atrophy as shown by biopsy a gluten free diet followed for a few months resulted in the complete disappearance of the urinary abnormalities and a considerable reduction in the mesangial deposits of $\operatorname{IgA}$. We therefore think that IgA-antigliadin antibodies should be looked for in all cases of "primary" IgA mesangial nephropathy so that the minority of patients in whom the renal disease is associated with a clinically unsuspected coeliac disease can be detected.

The mechanism of this association is unclear. As the incidence of IgA mesangial nephropathy is low in patients who have overt coeliac disease we think that the abnormality of the mucosal immune response that seems to characterise Berger's disease (increased activity of immunocompetent cells committed to producing IgA antibodies ${ }^{1314}$ ) must be present together with the jejunal lesions typical of coeliac disease for the renal disease to be manifest. This 
hypothesis is supported by the presence of IgA rheumatoid factor only in patients who have coeliac disease and IgA nephropathy and not in coeliac patients who do not have nephropathy.

The coexistence of these two specific disorders may explain why the proportion of patients in our population who had gliadin dependent mucosal lesions was definitely higher than that recently described by Hed $e t$ al in a large population of healthy blood donors screened for the presence of IgA-antigliadin antibodies. ${ }^{15}$ Both studies show that subclinical forms of coeliac disease are probably more common than was believed in the past and that in predisposed patients the renal disease may be its only clinical manifestation.

We thank Dr Paola Roggero for providing serum samples from the children with coeliac disease and Mrs Mascia Marchesini for typing the manuscript.

\section{References}

1 Hall RP, Stachura I, Cason J, Whiterside TL, Lawley TJ. IgA-containing circulating immune complexes in patients with IgA nephropathy. Am J Med 1983;74:56-63.

2 Woodroffe AJ, Gormly AA, McKenzie PE, et al. Immunologic studies in IgA nephropathy. Kidney Int 1980;18:366-74.
3 Coppo R, Basolo B, Martina G,et al. Circulating immune complexes containing IgA and IgM in patients with primary IgA nephropathy and with Henoch-Schönlein nephritis. Correlation with clinical and histologic signs of activity. Clin Nephrol 1982;18:230-9.

4 D'Amico G, Imbasciati E, di Belgioioso GB, et al. Idiopathic IgA mesangial nephropathy. Clinical and histological study of 374 patients. Medicine 1985;64:49-60.

D'Amico G. Idiopathic IgA mesangial nephropathy. Nephron 1985;41:1-13.

6 Amico G. Idiopachic 1 A mesangial nephropathy. Nephron 1985,41:1-13. idiopathic IgA mesangial nephropathy (Berger's disease). I I mmunol 1986;137:536-41.

7 Czerkinsky C, Koopman WJ, Jackson S, et al. Circulating immune complexes and immunoglobulin A rheumatoid factor in patients with mesangial immunoglobulin A nephropathies. J Clin Invest 1986;7:1931-8.

8 Emancipator S, Gallo G, Lamm M. Experimental IgA nephropathy induced by oral immunization. $\mathcal{J}$ Exp Med 1983;157:572-82.

9 Moorthy AU, Zimmerman SW, Maxim PE. Dermatitis herpetiformis and celiac disease: association with glomerulonephritis, hypocomplementemia and circulating immune complexes. JAMA 1978;239:2019-20.

10 Helin H, Mustonen J, Reunala T, Pasternack A. IgA nephropathy associated coeliac disease and dermatitis herpetiformis. Arch Pathol Lab Med 1983;107:324-7.

11 Kendall MJ, Cox PS, Schneider R, Hawkins CF. Gluten substractions in coeliac disease. Lancet 1972;ii:1065-7.

12 Pereira AB, Theophilopulos AN, Dixon FJ. Detection and partial characterization of circulating immune complexes with solid-phase anti-C3. I I mmunol 1980;125:763-72.

13 Egido J, Blasco R, Sancho J, Lozano L, Crespo MS, Hernando L. Increased rates of polymeric IgA synthesis by circulating lymphoid cells in IgA mesangial glomerulonephritis. Clin Exp Immunol 1982;47:309-16.

14 Egido J, Blasco R, Sancho J, Lozano L. T cell dysfunction in IgA nephropathy: specific abnormalities in the regulation of IgA synthesis. Clin Immunol Immunopathol 1983;26:201-11. 15 Hed J, Lieden G, Ottosson E, et al. IgA anti-gliadin antibodies and jejunal mucosal lesions in healthy blood donors. Lancet 1986;ii:215.

(Accepted 2 April 1987)

\title{
Alcohol consumption and the risk of alcohol related cirrhosis in women
}

\author{
ROBYN NORTON, ROBERT BATEY, TERENCE DWYER, STEPHEN MACMAHON
}

\begin{abstract}
The risks in women of cirrhosis with a likely primary alcohol aetiology were estimated for various levels of alcohol consumption in a case-control study. Data were obtained from 41 women with a first diagnosis of cirrhosis who had no evidence of non-alcohol-related cirrhosis; three matched controls were interviewed for each case. Significant increases in the risk of cirrhosis were detected at levels of consumption between 41 and $60 \mathrm{~g}$ daily; above this level a dose-response relation was observed. The risk of cirrhosis did not appear to be influenced by other nutritional factors or history of liver disease or use of hepatotoxic drugs. One per cent of Australian women consume more than $40 \mathrm{~g}$ alcohol daily, yet more than $90 \%$ of women identified with cirrhosis consumed alcohol at this level.

Preventive interventions to reduce alcohol consumption in the small group of women who consume more than $40 \mathrm{~g}$ daily have the potential to reduce substantially the incidence of alcohol related cirrhosis.
\end{abstract}

\footnotetext{
School of Public Health and Tropical Medicine, University of Sydney, Australia

ROBYN NORTON, PHD, MPH, research fellow

TERENCE DWYER, MD, MPH, senior lecturer Drug and Alcohol Unit, Department of Medicine, Westmead Centre, Sydney,
Australia

ROBERT BATEY, FRACP, MRCP, director

Department of Medicine, The Prince Henry Hospital, Sydney, Australia STEPHEN MACMAHON, PHD, research fellow

Correspondence and requests for reprints to: Dr R Norton, Academic Department of Medicine, Royal Free Hospital, London NW3 2QG.
}

\section{Introduction}

There is concern about the potential consequences of increasing alcohol consumption in women. ${ }^{12}$ It has been suggested that women may develop liver damage at low levels of daily alcohol consumption. ${ }^{34}$ Few data are available, however, from which to determine the level of alcohol consumption at which an important increase in the risk of alcohol related cirrhosis occurs. Furthermore, we do not know whether other factors such as hepatotoxic drug use or a history of other liver disease interact with alcohol to increase the risk of cirrhosis. $^{56}$

We report the results of a case-control study which was designed to determine in women the relative risks of cirrhosis with a likely primary alcohol aetiology at various levels of daily alcohol consumption. The role of several factors hypothesised to interact with alcohol in the development of alcohol related cirrhosis was also investigated.

\section{Subjects and methods}

Over 20 months (July 1982 to February 1984) all women with a first diagnosis of cirrhosis of the liver admitted to eight main hospitals in the Sydney metropolitan region were identified prospectively. Women were eligible for selection as cases if they resided in the Sydney metropolitan area, were not lifetime abstainers from alcohol, and did not have cirrhosis with a primary aetiology known not to be related to alcohol. Fifty two women met these criteria. Of these, seven were considered too ill to be interviewed and $41(91 \%)$ of the remainder consented to participate. In 37 of these women the hospital diagnosis indicated cirrhosis of probable primary alcohol aetiology. We judged 31 women to have "definite" cirrhosis on the basis of a liver biopsy (in 10), an isotope liver scan (in 16), or, when liver biopsy was contraindicated, standard clinical signs and biochemical tests ${ }^{7}$ (in five). In six women there was evidence of "possible" cirrhosis; in these cases liver biopsy was not contraindicated and diagnoses were based on clinical signs and biochemical tests alone. The remaining four women had hospital diagnoses of cryptogenic cirrhosis. In two of these women diagnoses were 